\title{
CLINICAL SPECTRUM OF DISEASE IN CHILDREN
}

\author{
David Isaacs
}

\subsection{Definitions}

3.2 Diagnosis

3.3 Clinical spectrum of disease

3.4 The common cold

3.5 Upper respiratory tract infections

3.5.1 Sinusitis

3.5.2 The catarrhal child

3.5.3 Pharyngitis and tonsillitis

3.5.4 Acute otitis media

3.6 Middle respiratory tract infections

3.6.1 Croup (acute laryngotracheitis)

3.6.2 Supraglottis

3.7 Lower respiratory tract infections

3.7.1 Bronchitis

3.7.2 Bronchiolitis

3.7.3 Pneumonia

3.8 Summary

3.9 References

\subsection{DEFINITIONS}

There have always been problems with the definitions of acute childhood respiratory infections. In 1965, when embarking on a Medical Research Council survey of childhood respiratory infections involving a number of hospitals, Donald Court noted that there was no generally accepted clinical classification of acute respiratory infections in children [11]. Paediatricians thought that they were all diagnosing the same disease, when making a clini-

Viral and Other Infections of the Human Respiratory Tract. Edited by S. Myint and D. Taylor-Robinson. Published in 1996 by Chapman \& Hall. ISBN 978-94-011-7932-4 cal diagnosis, but there was no evidence that this was true. Indeed quite the opposite appeared to be the case when the study was carried out. There was great variation in the diagnostic labels given to children with similar clinical presentations in different institutions that were geographically quite close. In four hospitals, for example, the proportion of all respiratory illnesses diagnosed as either bronchitis or bronchiolitis was almost constant, varying from $59 \%$ in Glasgow to $70 \%$ in Manchester. However, in Glasgow 52\% of all infections were called bronchitis and only $7 \%$ called bronchiolitis, whereas in Birmingham the reverse was true: $21 \%$ were called bronchitis and $45 \%$ bronchiolitis [11]. It seemed highly likely that different diagnostic labels were being applied to infected children in different centres, and that this reflected differing interpretation of signs and local diagnostic preferences.

To an extent, Court himself rectified this situation, by developing clear-cut definitions of acute childhood respiratory infections. These were scientifically based, in that the given frequency of signs and symptoms in each diagnostic category was based on the observed frequency during the survey (see Table 3.1). This was a seminal piece of work, and one that greatly facilitated later clinical studies. Like Scadding before him, Court appreciated the importance of clear definitions of diagnostic terms. 
Table 3.1 Definitions of acute respiratory infections. (From [11])*

\section{Upper respiratory infection syndrome}

Affected children are very frequently febrile with some or all of the following symptoms; red pharynx, red tonsils, with or without exudate, red ear drums, cough and nasal discharge. Abnormal signs in the lungs are infrequent and chest radiographs consistently normal.

\section{Individual categories}

Colds The principal symptom is excessive, mucoid or purulent, nasal discharge. This is very frequently associated with a red pharynx and with cough. From 6 months to 5 years, the illness is very frequently febrile.

Pharyngitis The principal symptom is redness of the pharynx. Children of all ages are very frequently febrile.

Tonsillitis The principal symptom is tonsillar redness, frequently with exudate, and very frequently with surrounding redness of the pharynx. Children of all ages are very frequently febrile.

Otitis media The principal symptom is marked redness of the ear drum, infrequently associated with perforation and discharge. A red pharynx is very frequent in children at all ages and nasal discharge frequent in children under 5 . Fever is very frequent in children under 5 but less so between 5 and 14 .

Middle respiratory infections

Croup (acute laryngitis or laryngotracheitis) Illness mainly affecting children between 6 months and 4 years. Stridor is the constant symptom, very frequently associated with hoarseness. Cough, breathlessness and chest recession are also very frequent. Upper respiratory features are generally present; red pharynx very frequently and nasal discharge frequently.

\section{Lower respiratory infections}

Acute bronchitis Illness affecting children mainly in the first 5 years of life. Cough is a constant symptom, and wheezing and breathlessness very frequent. Rhonchi are very frequently, and rales frequently, present. Upper respiratory symptoms, mainly red pharynx and nasal discharge, are frequent. The illness is very frequently febrile but high fever is infrequent. Except in a small minority chest radiographs are normal.

Acute bronchiolitis Illness mainly affecting infants, especially in the first 6 months of life. Rapid respiration, dyspnoea, wheezing, chest recession, cough, rhonchi and rales are very frequent. Visible distension of the chest and increased pulmonary translucency on the chest radiograph are frequent and of high diagnostic significance. Upper respiratory features, especially nasal discharge and a red pharynx are frequent. Fever is very frequent, but high fever uncommon.

Pneumonia Illness in which the essential feature is lobular segmental or lobar radiographic shadows, interpreted as pulmonary consolidation. Cough, rapid respiration, dyspnoea and rales are very frequent. Wheezing and chest recession are frequent in children under 5 , especially in the first year. Cyanosis is frequent in children under 5. Upper respiratory signs are frequent, especially nasal discharge and a red pharynx. In children aged from 5 to 14, chest pain, abdominal pain and headache are frequent, and they may also complain of body aches and shivering. Fever is very frequent at all ages.

* This table is based primarily on the frequency of each symptom. Very frequent indicates that the symptom was present in at least $50 \%$ of children in one or more of the four age groups in any particular category: frequent symptoms were present in 25-50\%; infrequent symptoms were present in 10-25\%.

\subsection{DIAGNOSIS}

The development and general application of rapid techniques for viral detection, and in particular immunofluorescence for respiratory syncytial (RS) virus, has been of major importance in resolving diagnostic differences between paediatricians. No longer did the paediatrician making a presumptive diagnosis of bronchiolitis have to wait 2 weeks for virological confirmation that the child, long since discharged home, was RS virus-positive. Instead his diagnosis could be lent substantial 
weight within a few hours of admission. Rapid diagnosis of RS virus was important, not so much because it helped paediatricians to avoid the unnecessary use of antibiotics, but because it helped them to refine their diagnostic accuracy.

Rapid viral diagnosis is available in only a few centres worldwide for other respiratory viruses. In Dr Pekka Halonen's laboratory in Turku, Finland, each specimen of nasopharyngeal secretion is tested by ELISA against a range of respiratory viruses, including RS virus, adenovirus, herpes simplex virus, parainfluenza viruses 1,2 and 3, and influenza viruses $A$ and B. Suspected adenovirus tonsillitis or adenoviral pharyngoconjunctival fever can be confirmed rapidly. Viral croup can be shown to be due to a parainfluenza virus in most cases. However, in these conditions there is not as much diagnostic confusion as in bronchiolitis, and the respiratory illnesses may be caused by a wider spectrum of respiratory viruses. Nevertheless, the more ready availability of rapid viral diagnosis would almost certainly help refine our clinical acumen and accuracy and would be beneficial for management.

\subsection{CLINICAL SPECTRUM OF DISEASE}

Most respiratory viruses are capable of causing a range of different clinical illnesses in children. Almost all can cause asymptomatic infection and some, like adenoviruses, may be carried in the nasopharynx and excreted for several months, without causing clinical illness. Many viruses can cause illnesses ranging from a mild cold or upper respiratory tract illness, through otitis media, laryngotracheobronchitis, to severe lower respiratory tract infection with bronchiolitis or pneumonia. In the cases of some viruses, like RS virus, re-infections of the same child are progressively less severe. Others, like rhinoviruses, may cause a mild cold in one child but precipitate a severe asthma attack in an asthmatic child of the same age.

The spectrum of respiratory disease in children can be considered primarily in one of two ways. The first is virus-orientated, and considers the spectrum of respiratory illness that can be caused by a single virus or group of viruses. This may be expressed in tabular form, as in Table 3.2, which gives the range of respiratory infections caused by adenoviruses.

The second approach is disease-orientated. In this approach, a clinical diagnosis is assigned to each child with a respiratory illness, and the viruses isolated in association with this illness are plotted. An example of this is given in Figure 3.1, which comes from a longitudinal study of children with recurrent respiratory infections ('index' group) and their siblings who did not have recurrent infections ('control' group) [22]. This study was undertaken at Northwick Park Hospital, and it was Dr David Tyrrell, one of my supervisors, who suggested the 'spectrum of illness' presentation of these

Table 3.2 Respiratory infections caused by adenoviruses

\begin{tabular}{lll}
\hline Illness & \multicolumn{1}{c}{ Comments } & Commonest types \\
\hline Tonsillitis or pharyngitis & Common; epidemics & $1,2,3,5,7$ \\
Pharyngoconjunctival fever & Common; epidemics & $2,3,4,5,7,14$ \\
Common cold & Rare; sporadic & $1,2,3,5,7$ \\
Pneumonia & Common; epidemics & $3,7,21$ \\
Acute respiratory disease (ARD) & Epidemics in military recruits & 4,7 \\
Laryngotracheitis (croup) & Rare; sporadic & $1,2,3,5,6,7$ \\
Bronchiolitis & Rare; sporadic & $3,6,21$ \\
Bronchiectasis & Rare complication & $3,7,21$ \\
Bronchiolitis obliterans & Very rare; late complication & 7,21 \\
\hline
\end{tabular}




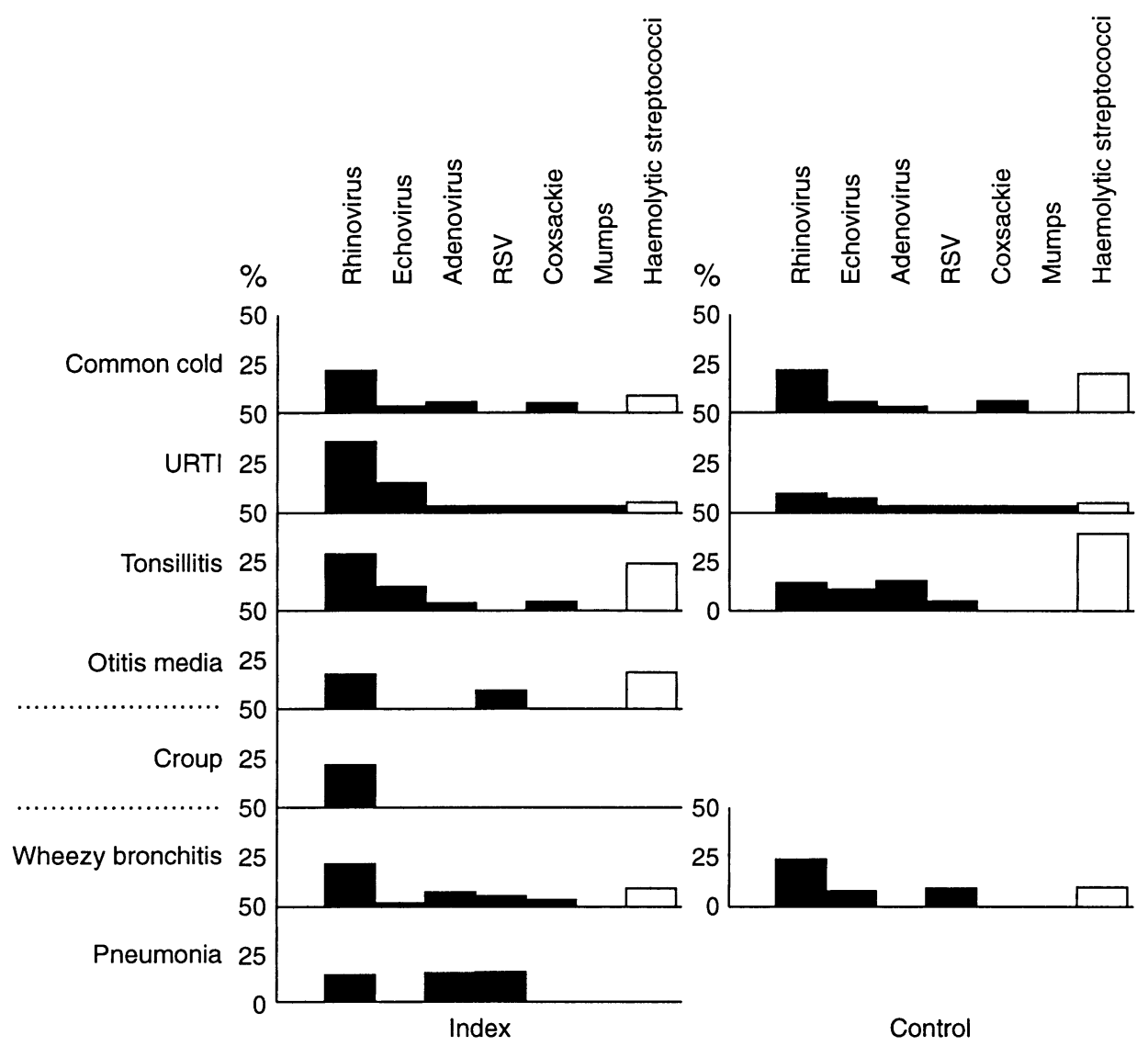

Figure 3.1 Clinical spectrum of disease in children: clinical diagnoses in children with recurrent infections (index) and their siblings (control) in association with different organisms.

data. The editors of the British Medical Journal disagreed and published the data tabulated numerically [27], but the graphic presentation in Figure 3.1 is, I believe, far more visually accessible to the reader.

\subsection{THE COMMON COLD}

The common cold, an illness characterized by mucoid or purulent nasal discharge, is the most common infectious disease of childhood, so well-deserves the adjective 'common'. However, more than 200 years ago, Benjamin Franklin recognized that colds were caught by exposure to other people and not to cold weather.
More than $50 \%$ of pre-school-age children with colds have fever, and pharyngitis and cough are also common features. Pre-school children have three to eight colds a year on average in developed countries $[4,7,13]$. These are generally caught within families, although the advent of child care facilities has revealed the latter as a potent source of respiratory infections.

The Common Cold Research Unit at Salisbury, England was at the forefront of early post-war studies on the spread of natural colds, even before cold viruses had been identified. Children from a local school with natural colds were invited to the Unit [32]. Volunteers 
got colds if they played table games with the children but not if they played cards using playing cards soiled with nasal secretions from the children. Further evidence for droplet spread was obtained by an experiment in which volunteers and children with colds in a hut were separated by a blanket across the hut. A fan from behind the children blew air over the blanket, and the volunteers got colds. Subsequent experiments have shown that rhinovirus-induced colds may be spread directly by contaminated secretions being rubbed into the nasal epithelium or conjunctiva, as well as by droplet spread [8]. Colds can be surprisingly difficult to spread in adults, even those in close contact, whereas there generally seems little problem spreading them among children [12]. This may reflect prior exposure to that strain or to similar strains of virus, and spread is also dependent on viral dose.

A number of different viruses can cause common colds in children, of which some are frequent causes and others are much rarer (see Table 3.3).

\subsection{UPPER RESPIRATORY TRACT INFECTIONS (URTIS)}

It is common practice in paediatrics to refer to children having URTIs or sometimes URIs (upper respiratory infections). Children with URTIs have something more than a cold but the infection is not sufficiently localized to be classified as pharyngitis, tonsillitis or otitis

Table 3.3 Viruses causing the common cold
Rhinoviruses
Coronaviruses
Parainfluenza viruses
Respiratory syncytial virus
Adenoviruses
Coxsackieviruses
Echoviruses
Influenza viruses
Reoviruses

media. The features of URTIs are fever, coryza, pink eardrums with intact light reflex, some pharyngitis, and cervical lymphadenopathy. URTI is an imprecise term, the use of which has often been discouraged, but it is a term used and understood by many general practitioners and paediatricians. That the term persists is an indication that it occupies a diagnostic niche not adequately covered by other diagnoses. Cervical lymphadenopathy is probably the most useful distinguishing clinical feature between URTIs and common colds. Viruses are the main cause of URTIs, and the responsible viruses are the same as those causing common colds [27] (Table 3.3).

Viral URTIs have been shown to be an important prodrome in $50 \%$ of episodes of invasive Haemophilus influenzae type b disease in pre-school children [38]. However, it has been consistently shown that prescribing oral antibiotics for children with URTIs does not prevent bacterial superinfection or other complications.

\subsubsection{SINUSITIS}

Infection of the paranasal sinuses is more difficult to diagnose clinically in children than adults, because facial pain and headache are rare. Ellen Wald, who has performed several important studies on sinusitis in children, describes 10 and 30 days of upper respiratory symptoms as important demarcation times. Most viral upper respiratory infections last 5-7 days, and the persistence of symptoms for 10 days is suggestive of the possibility of acute sinusitis. If symptoms persist for 30 days, subacute or chronic sinusitis should be considered [40].

\section{Clinical features}

The main features of sinusitis are persistent nasal discharge and cough [39]. The nasal discharge can be thin or thick, and can be clear or mucopurulent. The cough can be either dry or moist, and occurs in the day as well as at night. 
Clearly these non-specific symptoms may also occur in children with persistent respiratory infections without sinusitis, and also in atopic children with allergic rhinitis and asthma, although children with allergic rhinitis are likely to have an itchy nose. Other features which may suggest sinusitis are bad breath, and painless periorbital swelling in the morning. Fever is generally low-grade or absent, although occasionally high $\left(>39^{\circ} \mathrm{C}\right)$ with purulent nasal discharge. Children rarely complain of frontal headache, although older children may be tender over the frontal area.

Mild changes in sinus radiographs are common even in normal children, but complete opacification, dense mucosal thickening or air-fluid levels are strongly predictive of sinus infection. Computed tomography (CT) scans of the sinuses give better definition than plain radiographs in chronic sinusitis, but are unnecessary in acute sinusitis.

\section{Isolates}

Respiratory viruses are isolated from aspirated sinuses in about $10 \%$ of children with acute sinusitis, those most commonly detected being adenoviruses, parainfluenza viruses, influenza viruses and rhinoviruses. Bacteria, notably Streptococcus pneumoniae, untypable $H$. influen$z a e$, and Brarhamella catarrhalis, are isolated in about $75 \%$ of cases with clinical and radiological evidence of acute sinusitis. It is likely that respiratory virus infection predisposes to bacterial sinusitis, and that respiratory viruses are not cultured more often because viral specimens are collected late in the course of infection and the collection technique is often suboptimal.

\subsubsection{THE CATARRHAL CHILD}

John Fry, a general practitioner, wrote about The Catarhal Child, the child with a perpetual mucopurulent nasal discharge, hanging like candlesticks from each nostril [16]. The incidence of chronic mucopurulent nasal discharge is higher in indigenous children from poor, crowded family environments, such as many native American, African and Australian Aboriginal children. This suggests that recurrent or chronic infection might be an important aetiological factor in chronic catarrh. Indeed, in a study of preschool children with recurrent respiratory infections and healthy children, catarrhal children were found to have rhinitis most, but not all, of the time. Their nasal discharge cleared for a short time but then recurred, and different respiratory viruses, predominantly rhinoviruses, could be isolated at the start of each new episode [27]. What is more, the children were being infected more often but with the same spectrum of respiratory viruses as their 'healthy' siblings. Catarrh in these children, it seemed, was due to recurrent respiratory viral infections.

Sinusitis is another possible cause of chronic catarrh, and it is difficult to estimate what proportion of John Fry's catarrhal children [16] actually had chronic sinusitis.

A third possibility is that the child with chronic nasal discharge has perennial allergic rhinitis [30]. This is suggested clinically by a history of nasal stuffiness, itchiness and nasal blockage. The child continually rubs his or her nose, the 'allergic salute', a lateral crease may develop across the nose, the 'allergic crease', and dark rings under the eyes, 'allergic shiners'. Nasal smears show eosinophils and/or mast cells in allergic rhinitis [30].

\subsubsection{PHARYNGITIS AND TONSILLITIS}

Pharyngitis is inflammation of the mucous membranes of the pharynx, whereas tonsillitis involves predominantly tonsillar tissue. However, the two frequently coexist, viz. tonsillopharyngitis, and there may also be inflammation of the nose (nasopharyngitis), palate and uvula. Acute nasopharyngitis, in which there is high fever, sore throat and mucopurulent nasal discharge, is nearly always viral, with adenoviruses by far the most important cause. Other viral causes of nasopharyngitis are influenza 
viruses, parainfluenza viruses, rhinoviruses and RS virus. Adenoviruses are particularly likely to cause follicular pharyngitis or pharyngotonsillitis with exudate, an appearance identical to group A streptococcal tonsillitis [36]. The main distinguishing feature is age: most adenoviral pharyngotonsillitis occurs in children under 3 years of age, whereas group A streptococcal tonsillitis is rare under 5 years of age. Adenovirus infection often results in high fever and adenoviruses are an important cause of febrile convulsions [34].

Other important viral causes of exudative tonsillopharyngitis are Epstein-Barr virus, the so-called anginose form of glandular fever, primary herpes simplex virus infection, and parainfluenza viruses [33].

Pharyngoconjunctival fever, caused by adenoviruses 3 and 7, is a febrile pharyngitis with an intense conjunctivitis, which is usually unilateral or more severe in one eye if it is bilateral [36].

\subsubsection{ACUTE OTITIS MEDIA}

Acute otitis media (AOM) is a common infection, with about $60 \%$ of children experiencing at least one episode before a year of age, $20 \%$ in their second year of life, and 10-12\% each year until 6 years of age. Thereafter the incidence falls to less than $1 \%$ by the age of 12 years.

\section{Clinical features}

AOM is characterized clinically by fever, irritability and otalgia, and otoscopically by redness and bulging of the tympanic membrane and middle ear effusion. More than $90 \%$ of patients have concurrent upper respiratory signs such as rhinitis or cough, which precede the onset of acute otitis media by 3 to 7 days [1].

\section{Isolates}

Since bacteria are isolated from about $75 \%$ of episodes of AOM, and with refined bacteriological techniques from over $90 \%$, this condition is generally treated with antibiotics.
However, recent studies have emphasized the importance of viruses in childhood AOM, with viral antigens being detected or viruses isolated from middle ear fluid or nasopharyngeal aspirates in $30-60 \%$ of episodes of AOM $[1,9,18,35]$. This may be an underestimate of the prevalence of respiratory virus infection in AOM, because in many studies very few rhinoviruses are isolated. However, when Ohio HeLa cells are used, rhinoviruses are one of the most common viruses to be isolated from middle ear fluid [2,3]. Viruses appear to initiate swelling of the middle ear mucosa, and Eustachian tube obstruction, and predispose to superinfection with nasopharyngeal bacteria.

Episodes of acute otitis media that do not respond rapidly to antibiotics are more likely to have both bacteria and a virus present in middle ear fluid. It has been suggested that combined viral and bacterial infection may be important in the pathogenesis of chronic otitis media with effusion, sometimes called 'glueear', a common and important cause of conductive deafness in childhood [9].

\subsection{MIDDLE RESPIRATORY TRACT INFECTIONS}

\subsubsection{CROUP (ACUTE LARYNGOTRACHEITIS)}

Croup is a term used to describe respiratory illnesses characterized by inspiratory stridor, a barking cough like a seal, and a hoarse voice due to tracheal or laryngeal obstruction. It was originally an old English verb, 'to croup' meaning to croak. There are various causes of laryngotracheal obstruction, including foreign body and intubation trauma. Diphtheritic croup has been recognized since at least the fifteenth century. However, by convention the term croup is often now used as synonymous with viral laryngotracheitis.

Croup is not a particularly common respiratory infection, affecting less than $5 \%$ of children, predominantly those between 1 and 5 years of age. It is more common in boys. 


\section{Aetiology}

Parainfluenza virus type 1 is the most common cause of viral laryngotracheitis, tending to cause outbreaks in autumn or winter. Sometimes these epidemics occur every second year, but this pattern may change to annual outbreaks. Not uncommonly parainfluenza virus croup is also associated with wheezing, and the illness is best described as acute laryngotracheobronchitis.

Parainfluenzal virus type 2 virus can cause croup, but less frequently and less severely than type 1, and most type 2 infections are mild upper respiratory infections. Parainfluenza virus type 3 causes bronchiolitis and pneumonia in infants, but can cause croup in older children, which it does throughout the year without clear epidemics. The parainfluenza viruses, like RS virus, cause frequent successively milder reinfections, and older children and adults with colds can infect younger children.

A number of other viruses can cause croup. Influenza A virus can cause a severe laryngotracheitis, and children with such croup are more likely to require endotracheal intubation than those with croup due to parainfluenza viruses. Influenza B virus is a rarer and milder cause of croup. Other viral causes of croup include those viruses which can cause upper respiratory infections, such as rhinoviruses, adenoviruses, enteroviruses and RS virus. Coronavirus antigens have been detected in nasopharyngeal aspirates from children with croup [28]. Measles virus may also cause a significant tracheitis as part of acute measles.

\subsubsection{SUPRAGLOTTIS}

Over $95 \%$ of cases of epiglottis are caused by Haemophilus influenzae type b. However, there have been occasional cases of supraglottic inflammation where children have presented identically to epiglottis with acute laryngeal obstruction, but the only positive isolates have been viruses, parainfluenza or influenza virus being the usual cause [16a].

\subsection{LOWER RESPIRATORY TRACT INFECTIONS}

\subsubsection{BRONCHITIS}

Acute bronchitis is a febrile illness with cough, and usually with wheeze, which follows an upper respiratory infection. It has a number of synonyms and there is little agreement either within or between countries about a clear definition of acute bronchitis. For a number of years in the UK the condition was called wheezy bronchitis, although there is overlap with asthmatic or asthmatoid bronchitis. In America the name wheeze-associated respiratory illnesses (WARIs) was at one time proposed, but it never caught on. Unfortunately, as discussed previously, the term bronchiolitis is sometimes, and erroneously, used as synonymous with bronchitis.

\section{Clinical features}

Upper respiratory signs include rhinitis and often pharyngitis. The child is often tachypnoeic and dyspnoeic. Wheezing is usually audible on auscultation, and crackles are also audible in up to half the children. The chest radiograph must be normal or show only minor inflammatory changes, otherwise the condition is better classified as pneumonitis or pneumonia.

Acute bronchitis is extremely common in pre-school children. More than $20 \%$ of all children will have at least one episode by the age of 5 years $[10,31]$. Of these, approximately half will go on to have asthma, with recurrent wheezing. The younger the child with acute bronchitis the less likely they are to develop asthma. Boesen found that $3-7 \%$ of infants under 1 year of age who were admitted to hospital with a first attack of acute bronchitis developed asthma, compared with $18 \%$ of children 1-3 years old, and $42 \%$ of children over 3 [6]. Children are more likely to develop asthma if they are atopic or have a family history of atopic disease. However, not all asthmatics are atopic, and Frick among others has suggested that virus infections may cause bronchial mucosal damage allowing entry of inhaled 
allergens, and sensitization to these allergens [15]. His theory is that virus infections may themselves cause asthma, rather than that just trigger wheezing in atopic children. Certainly, Frick may be correct regarding non-atopic children, and it may also be that a significant respiratory virus infection is the main trigger for an atopic child to become asthmatic.

Acute bronchitis in infants under 1 year of age, which rarely leads to asthma, is probably caused predominantly by oedema and debris from exfoliated cells, resulting in obstruction of small bronchi and bronchioles. In asthmatic children with acute bronchitis the narrowing is also caused by constriction of bronchial wall smooth muscle, and is reversible by bronchodilator therapy.

\section{Viruses}

Most viruses that cause upper respiratory symptoms can also cause acute bronchitis. RS virus and parainfluenza virus type 3 are the major causes in many studies. However, where optimal techniques are used to isolate rhinoviruses, particularly the use of Ohio HeLa cells, these viruses are the main ones found, being responsible for more than half of all episodes in which a virus is detected [20-22,27]. Moreover, rhinoviruses can be isolated in high titre from sputum of older children with acute rhinovirus bronchitis [21].

Older children with acute bronchitis may well have asthma, and recurrent bronchitis is highly suggestive of asthma. Acute bronchitis does not respond to antibiotics, but may respond to anti-asthma treatment if there is a significant component of bronchospasm. Clearly, it is important always to consider asthma in children with acute bronchitis.

During a study on a highly selected group of pre-school children with recurrent respiratory infections, a small subgroup of four children was identified with frequent episodes of febrile cough and wheeze. These children did not produce interferon- $\alpha$ in response to virus infection in vitro [26]. The children were found not to lack major genes for interferon- $\alpha$, and indeed subsequently began to produce interferon- $\alpha$ normally. Other workers have subsequently confirmed these findings, identifying occasional children with impaired or delayed interferon- $\alpha$ production.

\subsubsection{BRONCHIOLITIS}

Bronchiolitis is a pathological description, otherwise inflammation of the bronchioles, that has come to be used as a clinical diagnosis, in the process engendering much confusion. One problem is that there may be inflammation of the bronchioles as well as the small bronchi during acute bronchitis and in asthmatics with wheezing secondary to respiratory viral infection. Nonetheless, the tendency to use the terms bronchiolitis and bronchitis interchangeably is an unfortunate one, and has contributed to varying reports of the rate of subsequent asthma in children with acute bronchiolitis.

\section{Clinical features}

The term bronchiolitis should be reserved for infants under 12 months of age who develop an acute respiratory infection characterized by cough, fever, tachypnoea, dyspnoea, hyperinflation and crackles. There may be sternal, subcostal and intercostal recession. Wheeze may occur but is by no means invariable. Cyanosis indicates severe disease. It can be seen, by comparing this clinical description with that for acute bronchitis (see Table 3.1), that there is overlap between the definitions and the potential for confusion. This can be minimized by restricting the diagnosis of bronchiolitis to infants under 1 year of age, and making a clinical diagnosis of bronchiolitis mainly during the epidemic season for respiratory syncytial virus (RS virus), which is the cause of over $70 \%$ of cases.

\section{RS virus}

$\mathrm{RS}$ virus causes an annual winter epidemic in temperate climates, and although the size and severity of the epidemic may vary from year to 
year, there is always an epidemic. In the tropics, in contrast, epidemics are much more variable in size and timing, tending to occur in the rainy season, if at all. There are two major subtypes of RS virus, A and B, and one or other subtype may predominate or both may circulate simultaneously.

Maternal antibody is poorly protective against RS virus, and babies may be infected shortly after birth. However, there is a 'honeymoon period' in the first 2 months of life when, although babies can be infected, this occurs less frequently than from 2-6 months of age. It is not clear whether this relative protection is due to a protective effect of passively acquired maternal antibody before this wanes, or because very young babies are cosseted and hence less likely to be exposed to infection.

Babies who are born pre-term and are infected with RS virus, even if they do not require artificial ventilation in the neonatal period and are some weeks old, may present initially with apnoeic episodes, before the illness evolves into florid bronchiolitis.

RS virus is ubiquitous. By the end of their second winter over $95 \%$ of children have been infected. Approximately $40 \%$ of infants infected with RS virus develop lower respiratory involvement and $1 \%$ are hospitalized. Reinfections with RS virus are common throughout life, and indeed $70 \%$ of adults can be infected by intranasal inoculation of RS virus [29]. Infections are successively milder, but neither specific serum nor secretory antibody to RS virus protects against re-infection. Thus, adults can be an important source of RS virus infection for babies at home and in hospital, although within families most RS virus is introduced by school-aged children.

\section{Infection}

RS virus is spread mainly by direct contact with nasal secretions, usually via hands though also by fomite spread on inanimate objects where the virus can survive for several hours. Hall and Douglas conducted a simple, elegant experiment on the mode of transmission of RS virus [17]. Adult volunteers were divided into three groups. The 'cuddlers' changed nappies, cuddled and fed RS viruspositive babies for a short period: five of seven of the adults acquired RS virus infection. The 'touchers' touched surfaces such as cot-sides and chest of drawers from an empty room recently vacated by a baby with $\mathrm{RS}$ virus, then rubbed their nose and eyes: four of 10 became infected. The 'sitters' sat 1.8 metres away from a baby with RS virus bronchiolitis for several hours, but touched nothing: none of 14 sitters was infected. Thus for RS virus, droplet spread appears to be an uncommon mode of transmission.

RS virus is by far the most common cause of bronchiolitis, being responsible for at least $70 \%$ of cases. However, outside the epidemic period for RS virus, an identical clinical picture may be caused by parainfluenza viruses, particularly type 3, by rhinoviruses, adenoviruses, influenza viruses, enteroviruses, and rarely by sporadic RS virus (Table 3.4). Children hospitalized with RS virus-induced bronchiolitis have an increased risk of developing asthma or at the very least have more reactive airways. In most studies approximately half of the children have subsequently developed recurrent wheezing.

Recovery from RS virus bronchiolitis depends mainly on T-cell function, and children with impaired T-cell function, either congenital or acquired due to HIV infection or cytotoxic therapy for leukaemia, are at risk of developing persistent, severe, symptomatic infection with wheeze and pulmonary infiltrates. In experiments carried out at Salisbury. shortly before the Common Cold Research Unit closed, $70 \%$ of adult volunteers infected with RS virus were shown to develop a specific cytotoxic $\mathrm{T}$-cell response directed against RS virus fusion protein or nucleoprotein [29]. The Salisbury studies and previous studies on babies with RS virus bronchiolitis [25] suggested that individuals who mounted a detectable specific cytotoxic T-cell response to $R S$ virus tended to have milder infections. 
Table 3.4 Relative frequency of virus isolation in acute respiratory infections of childhood

\begin{tabular}{|c|c|c|c|c|c|c|c|c|c|c|c|c|}
\hline & 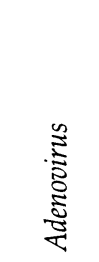 & 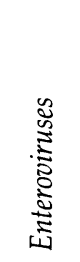 & 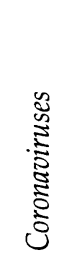 & 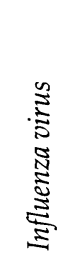 & 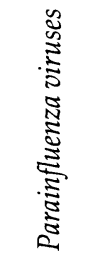 & 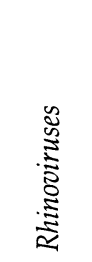 & $\begin{array}{l}\text { s } \\
\text { 离 } \\
\approx \\
\approx\end{array}$ & 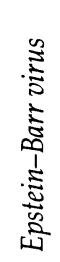 & 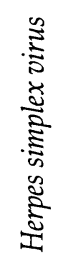 & 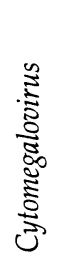 & 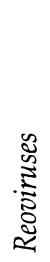 & 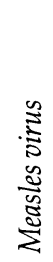 \\
\hline Common cold & + & t+ & +++ & + & + & $+++t$ & + & & & & + & \\
\hline Sinusitis & + & & & + & + & + & & & & & & \\
\hline Pharyngitis & ++++ & $++t$ & t+ & t+ & t+ & + & + & $+t$ & t+ & + & + & ++ \\
\hline Otitis media & ++ & + & + & + & + & $++t$ & ++ & & + & & & ++ \\
\hline Croup & +t & + & + & +++ & ++++ & + & ++ & & + & & + & + \\
\hline Bronchiolitis & & + & & + & ++ & + & ++++ & & & & & \\
\hline Bronchitis & + & + & ++ & ++ & +++ & ++++ & ++++ & & & & & ++ \\
\hline Pneumonia & t+ & + & + & + & ++ & $t++$ & ++++ & & + & & & $+t$ \\
\hline
\end{tabular}

Children and adults infected with RS virus produce very little nasopharyngeal interferon$\alpha$, in contrast to the situation with rhinovirus infections [24-26]. As RS virus is very sensitive to interferon in vitro, it was suggested that interferon might be used therapeutically in RS virus infections. However, studies at Salisbury showed that interferon given intranasally before infection could protect adult volunteers against RS virus infection, but was ineffective in treating volunteers with RS virus-induced colds [19].

\subsubsection{PNEUMONIA}

\section{Clinical features}

Pneumonia is a condition in which radiological features of pulmonary consolidation are present in conjunction with a clinical picture characterized by cough and fever. Tachypnoea and dyspnoea are common, and crackles are usually audible. Viral pneumonia is virtually impossible to distinguish clinically, radiographically or by simple laboratory tests from bacterial pneumonia [23]. Some authors have stated that wheeze is more likely in viral pneumonia, but formal studies have not confirmed this assertion [23].

\section{Histopathological types}

There are four major histopathological expressions of pneumonia: acute bronchiolitis, necrotizing bronchiolitis, interstitial pneumonia and alveolar pneumonia.

\section{Acute bronchiolitis.}

In this condition there is destruction of the bronchiolar ciliated respiratory epithelium. A degree of pulmonary shadowing, which could be called consolidation, is extremely common in acute bronchiolitis, and RS virus is a common cause of pneumonia as well as bronchiolitis in infancy. There is almost certainly great variation in the clinical and radiological interpretation of which babies have RS virus bronchiolitis, which have RS virus pneumonia, and which have both bronchiolitis and pneumonia. Indeed, in a number of studies in which a comparison has been made of the radiological interpretation of 'normal' and 'pneumonia' radiographs by experienced radiologists, there have been worrying discrepancies in interpretation of what constitutes consolidation [5,37], as well as an inability to differentiate viral from bacterial pneumonia $[5,23,37]$. 


\section{Necrotizing bronchiolitis.}

In this condition there is deep destruction of epithelial cells and submucosa lining the respiratory tract. It is most often seen in severe, often fatal pneumonia, usually caused by adenovirus types 3,7 or 21 .

\section{Interstitial pneumonia.}

This involves diffuse inflammation of the peribronchial alveolar septae with mononuclear cell infiltration. Radiographically there may be a diffuse, hazy pattern, sometimes described as interstitial pneumonitis, although this radiographic pattern of 'interstitial pneumonitis' does not necessarily coincide with a histopathological interstitial pneumonia. Fatal viral pneumonia usually has the histopathological features of bronchiolitis and interstitial pneumonia. Interstitial pneumonia or pneumonitis is more typical of non-bacterial causes of pneumonia, such as viruses, Pneumocystis carinii, Mycoplasma pneumoniae, and Chlamydia pneumoniae, than bacterial causes.

\section{Alveolar pneumonia.}

This is characterized by an intense alveolitis, with polymorphonuclear and mononuclear cell infiltrate, degeneration of alveolar cells and the formation of hyaline membranes. This pathological appearance is seen in fatal bacterial pneumonia.

\section{Clinical}

In children with viral pneumonia, there is generally a history of upper respiratory tract symptoms, such as coryza or sore throat, preceding the onset of respiratory distress by 1-2 days. Cough and fever are usual, although children with chlamydial pneumonitis are characteristically afebrile. Tachypnoea and dyspnoea may be associated with subcostal and intercostal recession, nasal flaring and sometimes grunting. Cyanosis is relatively uncommon. Young babies may develop apnoeic episodes.

\section{Aetiology}

Most viral pneumonias result from an initial upper respiratory infection, as suggested by the symptoms, followed by spread to the lower respiratory tract. The viruses involved include RS virus, parainfluenza viruses, influenza viruses, adenoviruses, measles and rhinoviruses. Some viruses, which are not usually classified as respiratory viruses, can cause pneumonia by haematogenous spread: these include the herpesviruses, varicella zoster virus (VZV), cytomegalovirus (CMV) and Epstein-Barr virus, all of which are most likely to cause pneumonia in immunocompromised children with impaired T-cell function. Children with impaired T-cell function also get more severe or atypical pneumonia with RS virus, parainfluenza viruses, influenza viruses and measles virus. Viruses acquired in the neonatal period may cause an intense, severe pneumonitis. Herpes simplex virus acquired from the maternal vaginal tract at delivery can cause a severe pneumonia at 3-7 days of age, which is almost always fatal unless treated early with acyclovir. Pregnant women who develop chickenpox 5 days before to 2 days after delivery, may transmit VZV transplacentally to the fetus. The baby is born well but, unless varicella-zoster immune globulin (VZIG) is given to the baby soon after birth, 30\% will develop a fatal pneumonitis at about 7 days of age.

\section{Incidence}

Viral pneumonia is predominantly a disease of pre-school children. The annual incidence of pneumonia under 5 years of age was 42 per 1000 in one study in the USA, compared with five per 1000 from 15-29 years of age [14]. Most pneumonias in children in developed countries are viral [23], perhaps as many as $90 \%$, whereas in developing countries bacterial 
pneumonia is much more common. Boys are affected 1.5 to 2 times more often than girls. Maternal smoking and air pollution in the urban environment are risk factors for pneumonia in infancy, and breast-feeding is protective. Pneumonia is most common in winter months in temperate climates. RS virus is the commonest cause of pneumonia, and winter peaks of pneumonia often coincide with the RS virus season. There may also be peaks when there are epidemics of other respiratory viruses such as parainfluenza virus 1 or influenza A virus. $M$. pneumoniae affects mainly school-age children in epidemics which occur every 3 to 4 years.

\subsection{SUMMARY}

Upper respiratory syndromes in childhood are relatively well defined. In contrast, there is considerable potential for diagnostic confusion between acute bronchitis, bronchiolitis and pneumonia. Respiratory viruses are generally capable of causing both upper and lower respiratory tract infections in children (see Table 3.4). Childhood respiratory virus infections are of major significance in their frequency of occurrence, morbidity and mortality, and their effect on family function.

\section{ACKNOWLEDGEMENTS}

I am privileged to have worked with David Tyrrell. I would also like to acknowledge my debt to Bernard Valman and David Webster at Northwick Park Hospital for initiating in me a love of the biology and immunology of respiratory viruses. At the John Radcliffe Hospital, Oxford my teachers in the immunology of respiratory viruses were Richard Moxon, Andrew McMichael, Charles Bangham, Frances Gotch and Alain Townsend, to all of whom I owe a great debt.

\subsection{REFERENCES}

1. Arola, M., Ruuskanen, O., Ziegler, T. et al. (1990) Clinical role of respiratory virus infection in acute otitis media. Pediatrics, 86, 848-55.
2. Arola, M., Ziegler, T., Ruuskanen, O. et al. (1988) Rhinovirus in acute otitis media. J. Pediatr., 113, 693-5.

3. Arola, M., Ziegler, T. and Ruuskanen, O. (1990) Prolonged respiratory virus infection as a cause of prolonged symptoms in acute otitis media. $J$. Pediatr., 116, 697-701.

4. Badger, G.F., Dingle, J.H., Feller, A.E. et al. (1953) A study of illness in a group of Cleveland families. II. Incidence of the common respiratory diseases. Am. J. Hyg., 58, 31-40.

5. Bettenay, F.A., de Campo, J.F. and McCrossin, D.B. (1988) Differentiating bacterial from viral pneumonia in children. Pediatr. Radiol., 18, 453-4.

6. Boesen, I. (1953) Asthmatic bronchitis in children; prognosis for 162 cases, observed 6-11 years. Acta Paediatr. (Uppsala), 42, 87-96.

7. Brimblecombe, F.S.W., Cruickshank, R., Masters, P.L. et al. (1958) Family studies of respiratory infections. Br. Med. J., 1, 119-28.

8. Bynoe, M.L., Hobson, D., Horner, J., Kipps, A., Schild, G.C. and Tyrrell, D.A.J. (1961) Inoculation of human volunteers with a strain of virus isolated from a common cold. Lancet, $\mathbf{i}$, 1194-6.

9. Chonmaitree, T., Owen, M.J., Patel, J.A. et al. (1992) Effect of viral respiratory tract infection on outcome of acute otitis media. J. Pediatr., $120,856-62$.

10. Colley, J.R.T. and Reid, D.D. (1970) Urban and social origins of childhood bronchitis in England and Wales. Br. Med. J., 2, 213-17.

11. Court, S.D.M. (1973) The definition of acute respiratory illnesses in children. Postgrad. Med. J., 49, 771-6.

12. Editorial (1988) Splints don't stop colds - surprising. Lancet, i, 277-8.

13. Fox, J.P., Hall, C.E., Cooney, M.K. et al. (1972). The Seattle virus watch. II. Objectives, study population, and its observation, data processing and summary of illnesses. Am. J. Epidemiol., 96, 270-85.

14. Foy, H.M., Cooney, M.K., McMahon, R. et al. (1973) Viral and mycoplasmal pneumonia in a prepaid medical care group during an eight year period. Am. J. Epidemiol., 97, 93-102. 
15. Frick, O.L., German, D.F. and Mills, J. (1979) Development of allergy in children. I. Association with virus infections. J. Allergy Clin. Immunol., 63, 228-41.

16. Fry, J. (1971) The Cattarrhal Child. Butterworth, London.

16a. Grattan-Smith, T., Forer, M., Kilham, H. and Gillis, J. (1987) Viral supraglottis. Pediatrics, 110, 434-5.

17. Hall, C.B. and Douglas, R.G. Jr (1981) Modes of transmission of respiratory syncytial virus. $J$. Pediatr., 99, 100-3.

18. Henderson, F.W., Collier, A.M., Sanyal, M.A. et al. (1982) A longitudinal study of respiratory viruses and bacteria in the etiology of acute otitis media with effusion. N. Engl. J. Med., 306, 1377-83.

19. Higgins, P.G., Barrow, G.I., Tyrrell, D.A.J., Isaacs, D. and Gauci, C.L. (1990) The efficacy of intranasal interferon $\mathrm{a}-2 \alpha$ in respiratory syncytial virus infection in volunteers. Antiviral Research, 14, 3-10.

20. Horn, M.E.C., Brain, E., Gregg, I., Yelland, S.J. and Inglis, J.M. (1975) Respiratory viral infection in childhood. A survey in general practice. Roehampton 1967-1972. J. Hyg. (Camb), 74, 157-68.

21. Horn, M.E.C., Reed, S.E. and Taylor. P. (1979) Role of viruses and bacteria in acute wheezy bronchitis in childhood: a study of sputum. Arch. Dis. Child., 54, 587-92.

22. Isaacs, D. (1984) The epidemiology and immunology of the syndrome of recurrent respiratory infections in pre-school children. MD Thesis. Cambridge University, England.

23. Isaacs, D. (1989) Problems in determining the etiology of community-acquired pneumonia. Pediatr. Infect. Dis. J., 8, 143-8.

24. Isaacs, D. (1989) Production of interferon in respiratory syncytial virus bronchiolitis. Arch. Dis. Child., 64, 92-5.

25. Isaacs, D., Bangham, C.R.M. and McMichael, A.J. (1987) Cell-mediated cytotoxic T-cell response to respiratory syncytial virus. Lancet, ii, 769-71.

26. Isaacs, D., Clarke, J.R., Tyrrell, D.A.J., Webster, A.D.B. and Valman, H.B. (1981) Deficiency of production of leucocyte interferon (interferona) in children with recurrent respiratory tract infections. Lancet, ii, 950-2.

27. Isaacs, D., Clarke, J.R., Tyrrell, D.A.J. and Valman, H.B. (1982) Selective infection of lower respiratory tract by respiratory viruses in children with recurrent respiratory tract infections. Br. Med. J., 284, 1746-8.

28. Isaacs, D., Flowers, D., Clarke, J.R., Valman, H.B. and Macnaughton, M.R. (1983) Epidemiology of coronavirus respiratory infections. Arch. Dis. Child., 58, 500-3.

29. Isaacs, D., MacDonald, N.E., Bangham, C.R.M., McMichael, A.J., Higgins, P.E. and Tyrrell, D.A.J. (1991) The specific cytotoxic T-cell response of adult volunteers to infection with respiratory syncytial virus. Immunol. Infect. Dis., 1,5-12.

30. Kemp, A. and Bryan, L. (1984) Perennial rhinitis. A common childhood complaint. Med. J. Aust., 141, 640-3.

31. Leeder, S.R., Corkhill, R.T., Irwig, L.M., Holland, W.W. and Colley, J.R.T. (1976) Influence of family factors on asthma and wheezing during the first five years of life. $B r . J$. Prevent. Soc. Med., 30, 213-18.

32. Lovelock, J.E., Porterfield, J.S., Roden, A.T., Somerville, T. and Andrewes, C.H. (1952) Further studies on the natural transmission of the common cold. Lancet, ii, 657-60.

33. Putto, A. (1987) Febrile exudative tonsillitis: viral or streptococcal? Pediatrics, 80, 6-12.

34. Rantala, H., Uhari, M. and Tuokko, H. (1990) Viral infections and recurrences of febrile convulsions. J. Pediatr., 116, 195-9.

35. Ruuskanen, O., Arola, M., Putto-Laurila, A. et al. (1989) Acute otitis media and respiratory virus infections. Pediatr. Infect. Dis. J., 8, 94-9.

36. Ruuskanen, O., Meurman, O. and Sarkkinen, H. (1985) Adenoviral disease in children: a study of 105 hospital cases. Pediatrics, 76, 79-83.

37. Stickler, G.B., Hoffman, A.D. and Taylor, W.F. (1984) Problems in the clinical and roentgenographic diagnosis of pneumonia in young children. Clin. Pediatr., 23, 398-9.

38. Takala, A.K., Meurman, O., Kleemola, M. et al. (1993) Preceding respiratory infection predisposing for primary and secondary invasive Haemophilus influenzae type $b$ disease. Pediatr. Infect. Dis. J., 12, 189-95.

39. Wald, E.R. (1992) Sinusitis in children. N. Engl. J. Med., 326, 319-23.

40. Wald, E.R., Guema, N. and Byers, C. (1991) Upper respiratory infections in young children: duration of and frequency of complications. Pediatrics, 87, 129-33. 